\title{
Avaliação bromatológica e perfil de ácidos graxos da carne de frangos de corte alimentados com rações contendo farinha de peixe ou aveia-branca
}

\author{
Daiana Novello${ }^{1}$, Paulo Roberto Ost ${ }^{2}$, Ricardo Alves da Fonseca ${ }^{3}$, Mikael Neumann², Sebastião \\ Gonçalves Franco ${ }^{4}$, Daiana Aparecida Quintiliano ${ }^{5}$
}

\author{
${ }^{1}$ Departamento de Nutrição da UNICENTRO - Universidade Estadual do Centro-Oeste - PR, Rua Camargo Varela de Sá, 03, Bairro Vila Carli, \\ CEP: 85040-080, Guarapuava - PR. \\ 2 Departamento de Medicina Veterinária - UNICENTRO - Universidade Estadual do Centro-Oeste. \\ 3 Universidade Estadual do Paraná, Faculdade Estadual de Filosofia, Ciências e Letras de Paranaguá. \\ ${ }^{4}$ Departamento de Pós-Graduação em Ciências Veterinárias da UFPR - Universidade Federal do Paraná. \\ ${ }^{5}$ Nutricionista, Especialista em Nutrição Clínica - UFPR - Universidade Federal do Paraná.
}

RESUMO - Objetivou-se analisar a composição química e o perfil de ácidos graxos (AG) da carne de frangos (peito e coxa/ sobrecoxa) alimentados com rações contendo farinha de peixe e aveia. O delineamento experimental foi inteiramente casualizado, com cinco tratamentos, três repetições e dez aves por unidade experimental. Como tratamentos, avaliaram-se rações contendo: 4,5 ou $9 \%$ de farinha de peixe; 10 ou $20 \%$ de aveia; e ração-testemunha. Não houve diferença significativa na composição química do peito. As amostras de coxa/sobrecoxa das aves alimentadas com dietas formuladas com $9 \%$ de farinha de peixe e $10 \%$ de aveia apresentaram maior quantidade de lipídios em comparação às obtidas com as rações controle e com $20 \%$ de aveia. A composição de ácidos graxos saturados, tanto do peito como da coxa/sobrecoxa, não diferiu entre as aves. A ração com $20 \%$ de aveia aumentou a quantidade de ácido palmitoléico no peito em comparação àquela com $9 \%$ de farinha de peixe. O acúmulo deste ácido graxo nas amostras de coxa/sobrecoxa foi maior nas aves alimentadas com as rações contendo aveia e menor naquelas alimentadas com $9 \%$ de farinha de peixe. Em comparação às rações com aveia, a ração com $9 \%$ de farinha de peixe apresentou maior potencial de aumento dos ácidos graxos poliinsaturados $\omega$-3 ( $\alpha$-linolênico) no peito e $\omega$-6 na coxa/sobrecoxa. Entretanto, a ração contendo $9 \%$ de farinha de peixe ocasionou maior acúmulo de $\omega$-3 na coxa/ sobrecoxa. A utilização de aveia na ração melhora o perfil de ácidos graxos monoinsaturados, especialmente o palmitoléico, enquanto a utilização de $9 \%$ de farinha de peixe na ração melhora o perfil dos ácidos graxos poliinsaturados, principalmente $\omega-6$ e $\omega-3$

Palavras-chave: aveia-branca, carcaça, farinha de peixe, frangos de corte

\section{Chemical evaluation and fatty acid profile of broilers meat fed diets with fish meal or white oat}

\begin{abstract}
The objective was to analyze the chemical composition and profile of fatty acids of broilers meat (breast and drumstick/thigh) fed diets with fish meal and oats. A completely randomized design, with five diets, three replications of 10 birds each, was used. Diets with 4.5 or $9 \%$ fishmeal, 10 or $20 \%$ oats, and control diet were evaluated. There was no difference in breast chemical composition. Drumstick/thigh of birds fed diets with $9 \%$ fishmeal and $10 \%$ oats showed greater amount of lipids than those fed control diet and diet with $20 \%$ oats. Composition of saturated fatty acids, as for breast and as for drumstick/thigh, did not differ between the birds. Diet with $20 \%$ oats increased the amount of palmitoleic acid in the breast in comparison to that with $9 \%$ fishmeal. Accretion of fatty acid in drumstick/thigh was higher in birds fed both diets with oats and lower in those fed diet with $9 \%$ fishmeal. Diet with $9 \%$ fishmeal showed greater potential to increase polyunsaturated fatty acids $\omega 3$ (alfa-linolenic) in breast and $\omega 6$ in drumstick/thigh, as compared to diets with oats. However, diet with $9 \%$ fishmeal showed greater accretion of $\omega 3$ in drumstick/thigh. Use of oats in diet improves the profile of monounsaturated fatty acids, especially palmitoleic acid, while use of $9 \%$ fish meal in diet improves the profile of $\omega 3$ and $\omega 6$ polyunsaturated fatty acids.
\end{abstract}

Key Words: broiler chickens, carcass, fish meal, white oat

Este artigo foi recebido em 25/1/2006 e aprovado em 4/3/2008.

Correspondências devem ser enviadas para nutridai@pop.com.br. 


\section{Introdução}

No Brasil, a avicultura é uma das atividades mais avançadas tecnologicamente, principalmente a de corte, com níveis de produtividade similares a países mais desenvolvidos.

Neste contexto, sabe-se que as carnes são alimentos preferidos pela maioria dos consumidores, mas, muitas vezes, são apontados como alimentos com alto teor de colesterol, gordura e ácidos graxos saturados e baixos níveis de insaturados (Bragagnolo, 2001). De acordo com Oliveira et al. (1992), Mahan \& Arlin (1994), Katch \& Mcardle (1996), Oliveira \& Marchini (1998) e Krummel (1998), os lipídios são macronutrientes energéticos formados por ácidos graxos (AG).

Um significativo número de pesquisas em humanos e animais acumulou-se ao longo de dois anos atestando a neutralidade dos AG monoinsaturados (MUFAs) na elevação dos níveis de colesterol sérico. Estudos mais atualizados mostram que, quando se substituem os ácidos graxos saturados por MUFA os níveis de LDL diminuem enquanto HDL permanece inalterado (Monteiro et al., 1993; Denker, 1994; Matherson et al., 1996).

Os ácidos graxos poliinsaturados (PUFA) naturalmente são benéficos, pois reduzem agregações das plaquetas e os triglicerídeos e, conseqüentemente, o risco de doenças cardíacas (Kinsella et al., 1990). Classificam-se por serem considerados essenciais, pois o organismo não os produz, portanto, devem ser ingeridos pela alimentação diária, que são os ômega $6(\omega-6,18: 2)$ e ômega $3(\omega-3,18: 3)$ (Mahan \& Arlin, 1994). Atualmente os ácidos graxos considerados essenciais são $\alpha$-linolênico e linoléico (Oliveira et al., 1992).

A farinha de peixe é elaborada a partir de uma grande variedade de espécies de peixe. Tem excelente balanço de aminoácidos, sendo rica em metionina e lisina, cálcio e fósforo (Butolo, 2002; Fialho, 2004; Ribeiro et al., 2005). Em geral, é rica em AG $\omega$-3, porém o método de processamento e refinamento influencia no seu conteúdo.

Segundo Macleod et al. (2004), a aveia-branca (Avena sativa L.) contém concentração alta de PUFA e atividade antioxidante significante e pode conferir benefícios na qualidade de carne. Os efeitos na qualidade de carne incluem melhora do sabor, em razão da diminuição na rancidez do alimento, da maciez e da baixa perda de líquidos que provocam vida de prateleira mais longa.

Este trabalho foi realizado com o objetivo de avaliar o efeito da utilização de aveia e farinha de peixe em rações sobre a composição bromatológica e o perfil de ácidos graxos da carne de frango.

\section{Material e Métodos}

O experimento foi conduzido no Laboratório de Nutrição Animal do Departamento de Nutrição do CCS da Universidade Estadual do Centro-Oeste do Paraná - UNICENTRO, em Guarapuava, Paraná, no período de janeiro a dezembro de 2004.

Foram utilizados 150 frangos de corte machos de linhagem Ross, com peso médio inicial de 38 g, criados de 1 a 40 dias de idade, alojados em gaiolas. $\mathrm{O}$ ambiente foi climatizado durante todo o período experimental para maior conforto térmico dos animais.

Para a realização do estudo, os animais do experimento receberam as rações-teste e ração-referência. Os tratamentos (T) experimentais foram os seguintes: 1- ração-referência; $2-4,5 \%$ de farinha de peixe; $3-9 \%$ de farinha de peixe; 4 $10 \%$ de aveia-branca; 5 - 20\% de aveia-branca. As rações foram isoprotéicas e isoenergéticas.

Os dois alimentos-teste foram incluídos em uma raçãoreferência (Tabela 1), calculada segundo Rostagno et al. (2000). Ração e água foram fornecidos ad libitum. Durante o período experimental, foi utilizada apenas uma única ração, pois foi considerada uma só fase durante o experimento. Isso pode ser justificado na tentativa de manter os mesmos níveis dos alimentos-teste do início ao final do experimento, para evitar modificações que pudessem influenciar o valor nutricional da carne a ser avaliada.

No experimento foi utilizado o delineamento inteiramente casualizado, com cinco tratamentos, três repetições de cada tratamento e dez aves por unidade experimental, perfazendo um total de 150 animais.

No final do período experimental, aos 40 dias de idade, todas as aves de cada parcela foram pesadas, em balança com divisão de $5 \mathrm{~g}$, sendo separado um animal de cada repetição, com peso próximo ao peso médio da parcela. Após jejum de 6 horas, as aves foram sacrificadas e congeladas a $-18^{\circ} \mathrm{C}$.

As carcaças foram descongeladas em refrigerador com temperatura aproximada de $10^{\circ} \mathrm{C}$ por 48 horas. Foram então retiradas das amostras de peito e de coxa/sobrecoxa toda a gordura visível, a pele, as cartilagens e os ossos, restando somente tecido muscular. Essa carne foi moída em processador até atingir consistência pastosa para as análises de umidade e cinzas no laboratório de Engenharia de Processos do Departamento de Engenharia de Alimentos da UNICENTRO em Guarapuava, Paraná. As amostras restantes foram colocadas em bandejas etiquetadas e secas em estufa com ar circulante a $55^{\circ} \mathrm{C}$ por 48 horas para retirada da umidade. As amostras secas foram enviadas para o Laboratório de Análises Físico-Químicas da EMBRAPA 
Tabela 1 - Composição das rações experimentais

\begin{tabular}{|c|c|c|c|c|c|}
\hline$\frac{\text { Ingrediente }}{\text { Milho grão }}$ & $\frac{\text { Ração-referência }}{59,30}$ & \multicolumn{2}{|c|}{ Farinha de peixe (\%) } & \multicolumn{2}{|c|}{ Aveia-branca (\%) } \\
\hline Soja farelo $45 \%$ & 34,33 & 28,36 & 22,84 & 33,84 & 33,58 \\
\hline Aveia-branca & - & - & - & 10,00 & 20,00 \\
\hline Óleo de soja & 1,98 & 1,19 & 2,57 & 2,50 & 4,05 \\
\hline Fosfato bicálcico & 1,78 & 0,90 & 0,71 & 1,77 & 1,76 \\
\hline Calcário calcítico & 0,96 & 0,85 & 0,50 & 0,95 & 0,94 \\
\hline Dl-metionina 99 & 0,23 & 0,20 & 0,15 & 0,22 & 0,22 \\
\hline L-lisina $\mathrm{HCl}$ & 0,18 & 0,16 & 0,10 & 0,18 & 0,17 \\
\hline Premix vitamínico-ave ${ }^{1}$ & 0,20 & 0,19 & 0,14 & 0,20 & 0,20 \\
\hline Premix mineral-ave ${ }^{2}$ & 0,10 & 0,10 & 0,04 & 0,10 & 0,10 \\
\hline \multicolumn{6}{|l|}{ Composição calculada } \\
\hline Metionina + cistina total, \% & 0,88 & 0,88 & 0,88 & 0,88 & 0,88 \\
\hline Metionina total, \% & 0,55 & 0,56 & 0,55 & 0,54 & 0,54 \\
\hline Lisina total, $\%$ & 1,24 & 1,24 & 1,24 & 1,24 & 1,24 \\
\hline Triptofano total, \% & 0,26 & 0,24 & 0,23 & 0,26 & 0,27 \\
\hline Treonina total, \% & 0,84 & 0,86 & 0,86 & 0,88 & 0,86 \\
\hline $\mathrm{Na}, \%$ & 0,22 & 0,22 & 0,22 & 0,22 & 0,22 \\
\hline Cloro, \% & 0,30 & 0,30 & 0,29 & 0,29 & 0,28 \\
\hline Potássio, \% & 0,81 & 0,74 & 0,66 & 0,81 & 0,81 \\
\hline Ácido linoléico, \% & 2,44 & 1,68 & 1,65 & 2,53 & 3,16 \\
\hline Fibra bruta, \% & 3,39 & 3,40 & 3,67 & 4,53 & 5,23 \\
\hline Gordura total, \% & 5,27 & 4,15 & 5,05 & 5,90 & 7,60 \\
\hline
\end{tabular}

${ }^{1}$ Mistura vitamínica: vit. A - $10.000 \mathrm{UI}$; vit. $\mathrm{D}_{3}-2.000 \mathrm{UI}$; vit. E - $30 \mathrm{UI}$; vit. $\mathrm{B}_{1}-2,0 \mathrm{mg}$; vit. $\mathrm{B}_{2}-6,0 \mathrm{mg}$; vit. $\mathrm{B}_{6}$ - 4,0 mg; vit. $\mathrm{B}_{12}-0,015 \mathrm{mg}$; ácido pantotênico - 12,0 mg; biotina - 0,1 mg; vit. $\mathrm{K}_{3}-3,0 \mathrm{mg}$; ácido fólico - 1,0 mg; ácido nicotínico - 50,0 mg.

2 Mistura mineral: Fe - 50 mg; Co - 1,0 mg; Cu - 10,0 mg; Mg - 80,0 mg; Zn - 50,0 mg; I - 1,0 mg.

Tabela 2 - Composição de ácidos graxos saturados, monoinsaturados e poliinsaturados (g/100 g) das rações experimentais

\begin{tabular}{|c|c|c|c|c|c|}
\hline \multirow[t]{2}{*}{ Ácido graxo } & \multirow[t]{2}{*}{ Ração-referência } & \multicolumn{2}{|c|}{ Farinha de peixe (\%) } & \multicolumn{2}{|c|}{ Aveia-branca (\%) } \\
\hline & & 4,5 & 9 & 10 & 20 \\
\hline \multicolumn{6}{|l|}{ Saturados } \\
\hline $\begin{array}{l}\text { Ácido mirístico C14:0 } \\
\text { C16:0 } \\
\text { Ácido esteárico C18:0 } \\
\text { Total }\end{array}$ & $\begin{array}{c}0,18 \\
11,23 \\
3,49 \\
14,90\end{array}$ & $\begin{array}{c}0,44 \\
15,65 \\
3,26 \\
19,35\end{array}$ & $\begin{array}{c}1,150 \\
18,52 \\
3,94 \\
23,61\end{array}$ & $\begin{array}{c}\text { ND } \\
12,61 \\
3,10 \\
15,71\end{array}$ & $\begin{array}{c}0,06 \\
12,19 \\
3,77 \\
16,02\end{array}$ \\
\hline $\begin{array}{l}\text { Ácido palmitoléico C16:1, } \omega-7 \text { cis } \\
\text { Ácido oléico C18:1, } \omega-9 \text { cis } \\
\text { Ácido 11-cis-eicosenóico C20:1, } \omega-9 \text { cis } \\
\text { Total MUFAs }\end{array}$ & $\begin{array}{c}\mathrm{ND} \\
28,01 \\
0,17 \\
28,18 \\
\end{array}$ & $\begin{array}{c}0,65 \\
32,17 \\
0,16 \\
32,98 \\
\end{array}$ & $\begin{array}{c}1,34 \\
32,56 \\
\text { ND } \\
33,90 \\
\end{array}$ & $\begin{array}{l}\text { ND } \\
28,46 \\
\text { ND } \\
28,46 \\
\end{array}$ & $\begin{array}{c}0,10 \\
27,02 \\
0,36 \\
27,48 \\
\end{array}$ \\
\hline \multicolumn{6}{|l|}{ Poiliinsaturados } \\
\hline
\end{tabular}

As análises são expressas em base de matéria seca.

ND - Não disponível. 
Suínos e Aves, localizada na cidade de Concórdia, Santa Catarina, para análises e determinação dos teores de proteína bruta e extrato etéreo e perfil de ácidos graxos.

As amostras da carne e das rações foram analisadas quanto à umidade e cinzas segundo metodologia descrita pelo Instituto Adolfo Lutz (1985). As proteínas totais foram quantificadas em duplicata, pelo clássico método MicroKjedahl (AOAC, 1995a).

As análises dos ácidos graxos foram realizadas em matéria seca utilizando-se a metodologia descrita por Hartman \& Lago (1986). A identificação dos ácidos graxos foi feita por comparação dos triglicerídeos dos ésteres metílicos da amostra com os triglicerídeos de padrões autênticos (ésteres metílicos Sigma). A análise de lipídios totais foi realizada segundo metodologia AOAC (1995b).

Na determinação das análises químicas das rações, as rações foram embaladas em sacos plásticos hermeticamente fechados e enviadas para avaliação da composição nutricional em relação à umidade, cinzas, proteína bruta, extrato etéreo e ácidos graxos. Da mesma forma como as análises da carne dos frangos, as análises de umidade e cinzas das rações foram realizadas no Laboratótio de Engenharia da UNICENTRO em Guarapuava, Paraná, de modo que proteína bruta, extrato etéreo e os ácidos graxos foram analisados no Laboratório de Análises FísicoQuímicas da EMBRAPA Suínos e Aves, localizada na cidade de Concórdia, Santa Catarina. As metodologias utilizadas para avaliar as rações foram as mesmas descritas para análise da carne dos frangos.

Os valores de composição química de carcaça foram comparados aos das Tabelas de composição química de alimentos nacionais e internacionais para humanos: Tabela Brasileira de Composição de Alimentos - TACO (2004) e United States Department of Agriculture - USDA (1999).

Os dados estatísticos foram analisados utilizando-se o programa estatístico SISVAR (Ferreira, 1999), a 5\% de significância utilizando teste Tukey.

\section{Resultados e Discussão}

Não foram encontrados valores diferentes (Tabela 3) para umidade, cinzas, proteína bruta e extrato etéreo na carne de peito dos frangos. Entretanto, houve aumento do extrato etéreo na coxa/sobrecoxa nas rações contendo 9\% de farinha de peixe e $10 \%$ de aveia-branca em comparação à ração-referência e com 20\% de aveia-branca. A ração com $20 \%$ de aveia, apesar de ter sido aquela com maior teor de gordura, 7,6\% (Tabela 2), ocasionou menor teor desse nutriente na coxa/sobrecoxa, o que pode estar relacionado ao maior teor de fibra dessa ração, uma vez que a fibra pode ter dificultado a absorção de gordura.

Valores inferiores aos obtidos nesta pesquisa foram relatados por Torres et al. (2000), que realizaram análises da composição centesimal de cortes de carne de frangos e encontraram para a coxa de frango 70,51g/100 g de carne e, para a carne do peito, 73,81 g/100 g. Esses mesmos autores obtiveram valores de cinzas de $0,78 \mathrm{~g} / 100 \mathrm{~g}$ para a coxa e 1,10 g/100 g para o peito. Valores superiores, no entanto, foram obtidos por esses autores para os teores de lipídios e proteínas da coxa de frango (9,32 g/100 g e 18,09 g/100 g de matéria natural, respectivamente), que observaram na carne de peito em torno de 1,84 g/100 g de lipídios e 20,80 g/100 g de proteínas.

De forma geral, observa-se uma variação considerável dos valores da literatura, no entanto alguns valores precisam ser observados, cujos teores de lipídios na coxa/sobrecoxa foram mais baixos que os deste estudo e que demonstram que os cinco tipos de rações avaliadas resultaram em carne de melhor qualidade para consumo.

Os teores médios de lipídios totais desta pesquisa para carne branca (peito) foram inferiores ao encontrado na Tabela de Composição de Alimentos da USDA (1999), que é 1,65 g/100 g do alimento em matéria natural, forma de consumo do alimento. A quantidade de proteína apresentada pela Tabela da USDA (1999) é de 23,2 g/100 g. Nessa mesma tabela, são descritos para a carne da coxa crua valores de 4,31 g/100 g de lipídios e 20,08 g/100 g de proteínas. Os resultados de umidade e cinzas otidos nesta pesquisa em ambos os cortes avaliados, são semelhantes aos descritos nessa Tabela.

Quando os resultados foram comparados com a Tabela Brasileira de Composição de Alimentos - TACO (2004), observou-se que esta Tabela informa valores superiores de lipídios e proteína no peito (3 g/100 g e 22 g/100 g de matéria natural, respectivamente) de frango e semelhantes de lipídios e superiores de proteína na coxa/sobrecoxa ( 5 g/100 g e $18 \mathrm{~g} / 100 \mathrm{~g}$, respectivamente). Comparando-se os dados de umidade e cinzas deste estudo com a Tabela TACO (2004), observaram-se valores semelhantes aos encontrados para a porção do peito, e na coxa verifica-se quantidade superior de umidade, mas próxima das cinzas. Estes resultados discrepantes indicam que os valores das Tabelas de Composição Química de Alimentos devem ser constantemente revistos, uma vez que podem ser influenciados por diversos fatores relacionados à nutrição das aves, à genética e ao próprio processamento das carnes.

Não houve diferença entre as rações quando avaliados os ácidos graxos saturados mirístico, palmítico e esteárico, 
Tabela 3 - Composição química da carne de peito de frangos de corte alimentados com as rações-teste

\begin{tabular}{|c|c|c|c|c|c|c|}
\hline & $\begin{array}{l}\text { Umidade } \\
(\%)\end{array}$ & $\begin{array}{c}\text { Cinzas } \\
(\%)\end{array}$ & $\begin{array}{c}\text { Proteína bruta* } \\
(\%)\end{array}$ & $\begin{array}{c}\text { Proteína bruta** } \\
(\%)\end{array}$ & $\begin{array}{c}\text { Extrato etéreo* } \\
(\%)\end{array}$ & $\begin{array}{c}\text { Extrato etéreo** } \\
(\%)\end{array}$ \\
\hline \multicolumn{7}{|c|}{ Peito } \\
\hline Farinha de peixe, $4,5 \%$ & $74,78 a$ & $1,16 a$ & $84,79 a$ & $20,16 a$ & $6,32^{\mathrm{a}}$ & $1,56 a$ \\
\hline Farinha de peixe, 9\% & $73,68 a$ & $1,15 a$ & $84,53 a$ & $21,33 a$ & $4,10^{\mathrm{a}}$ & $1,07 a$ \\
\hline Aveia-branca, $10 \%$ & $74,44 a$ & $1,05 a$ & $83,90 a$ & $20,52 a$ & $4,31^{\mathrm{a}}$ & $1,10 \mathrm{a}$ \\
\hline Erro-padrão da média & 0,99 & 0,08 & 0,78 & 0,86 & 0,53 & 0,13 \\
\hline CV $(\%)$ & 2,31 & 11,16 & 1,61 & 7,13 & 19,48 & 19,26 \\
\hline \multicolumn{7}{|c|}{ Coxa/sobrecoxa } \\
\hline Ração-referência & $75,62 \mathrm{a}$ & $1,07 \mathrm{a}$ & $82,93 a$ & $15,99 a$ & $18,45 a$ & $4,51 \mathrm{a}$ \\
\hline Farinha de peixe, $4,5 \%$ & $72,88 a$ & $1,04 \mathrm{a}$ & $83,17 a$ & $18,04 \mathrm{a}$ & $18,83 a b$ & $5,10 \mathrm{ab}$ \\
\hline Erro-padrão da média & 0,99 & 0,06 & 0,87 & 0,58 & 0,64 & 0,28 \\
\hline CV $(\%)$ & 2,35 & 10,52 & 1,83 & 5,91 & 5,54 & 9,15 \\
\hline
\end{tabular}

Medidas na coluna seguidas de letras iguais não diferem $(P>0,05)$ significativamente pelo teste Tukey.

* As análises são expressas em base de matéria seca.

** As análises são expressas em base de matéria natural.

tanto na carne do peito como na coxa/sobrecoxa dos frangos analisados, mesmo que nas rações avaliadas tenham sido observados valores mais altos de alguns desses ácidos, por exemplo, o ácido palmítico da ração com 9\% de farinha de peixe (Tabela 2).

Ratnayake et al. (1989) pesquisaram frangos alimentados com 4, 8 e 12\% de farinha de peixe. Os valores de ácidos graxos saturados das carnes, tanto na coxa como no peito, dessas aves, não apresentaram diferença significativa entre os três níveis de farinha, concordando com este trabalho. Entretanto, a quantidade de AG C:16 foi a maior em ambos os cortes.

Souza et al. (1999), que avaliaram a carne de frango assada, verificaram na coxa e no peito sem pele, valores menores de C14:0, C16:0 e C18:0 (0,01; 0,31 e 0,12 g/100 g, respectivamente, no peito de frango e 0,$03 ; 1,18$ e $0,39 \mathrm{~g} / 100$ g, respectivamente, na coxa de frango).

Estudos de Bragagnolo \& Rodriguez-Amaya (1992, 1995) indicam total para carne de peito de $0,84 \mathrm{~g} / 100 \mathrm{~g}$ de ácidos graxos saturados, e 2,18 g/100 g para carne de coxa/ sobrecoxa. Quanto aos ácidos graxos MUFA, relataram valores de 1,17 g/100 g para o peito e 3,04 g/100 g em frangos coletados no estado de São Paulo.

Grande (1962) relatou que ácidos graxos com comprimento de cadeia variando de 4 a 10 átomos de carbono não são capazes de aumentar o colesterol sérico. Contudo, os ácidos graxos saturados láurico (CI 2:0) (Bonanome \& Grundy, 1988) e mirístico (C14:0) (Keys et al., 1965) são considerados hiperlipidêmicos. Neste trabalho, como as rações utilizadas não demonstraram diferenças nos cortes avaliados de peito e coxa/sobrecoxa, entre os ácidos graxos saturados mirístico, palmítico e esteárico, poderão ser administradas às aves sem causar danos, tanto aos animais como para as pessoas que irão consumir a carne.

A concentração dos ácidos graxos palmitoléico no peito dos frangos (Tabela 5) diferiu significativamente entre a ração com $9 \%$ de farinha de peixe e aquela com $20 \%$ de aveia e foi maior na ração com $9 \%$ de farinha de peixe teve teor mais elevado (Tabela 2). Na coxa/sobrecoxa, a ração com $10 \%$ de aveia foi superior àquela com $9 \%$ de farinha de peixe. As concentrações dos ácidos graxos oléico e 11-cis eicosenóico, em ambos os cortes, não diferiram entre as rações.

Nas amostras de coxa/sobrecoxa (Tabela 5), assim como no peito, entre os MUFA apenas o ácido graxo palmitoléico diferiu significativamente entre as aves. Entretanto, a carne das aves alimentadas com 9\% de farinha de peixe apresentou menor quantidade deste ácido graxo em comparação àquelas com aveia-branca.

Souza et al. (1999), analisando a carne de frango assada, verificaram no peito sem pele valores menores de C16:1 e C18:1 de 0,07 e 0,56 g/100 g respectivamente, e, na coxa sem pele, os valores de C16:1 e C18:1, 0,30 e 2,32 g/100 g. Esses autores observaram ainda que, entre os ácidos graxos MUFA, o que apresentou maior quantidade foi o oléico e, na coxa, observaram maior quantidade em relação ao peito. 
Tabela 4 - Composição de ácidos graxos saturados $(\mathrm{g} / 100 \mathrm{~g})$ da carne de peito e de coxa/sobrecoxa dos frangos avaliados

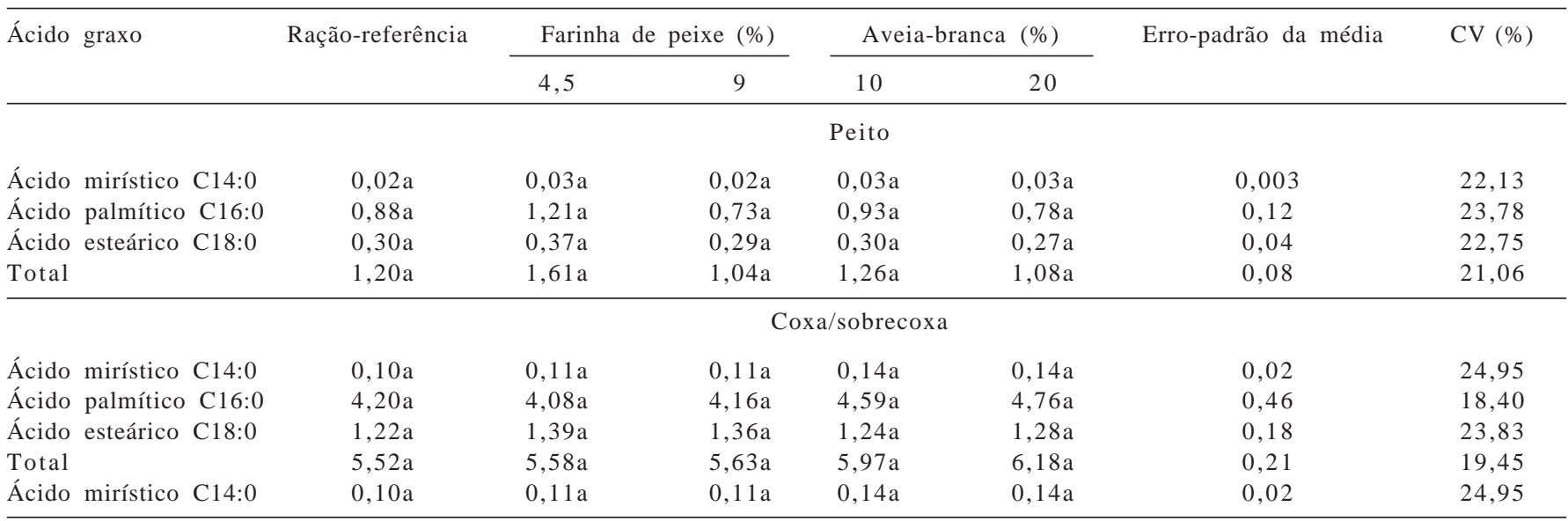

Medidas na linha seguidas de letras iguais não diferem $(P>0,05)$ significativamente pelo teste Tukey.

As análises são expressas em base de matéria seca.

Tabela 5 - Composição química de ácidos graxos monoinsaturados (g/100 g) da carne de peito e coxa/sobrecoxa dos frangos avaliados

\begin{tabular}{|c|c|c|c|c|c|c|c|}
\hline \multirow[t]{2}{*}{ Ácido graxo } & \multirow[t]{2}{*}{ Ração-referência } & \multicolumn{2}{|c|}{ Farinha de peixe (\%) } & \multicolumn{2}{|c|}{ Aveia-branca (\%) } & \multirow[t]{2}{*}{ Erro-padrão da média } & \multirow[t]{2}{*}{ CV (\%) } \\
\hline & & 4,5 & 9 & 10 & 20 & & \\
\hline & \multicolumn{7}{|c|}{ Peito } \\
\hline $\begin{array}{l}\text { Ácido palmitoléico } \\
\text { C16:1, } \omega-7 \text { cis }\end{array}$ & $0,18 a b$ & $0,18 a b$ & $0,12 \mathrm{a}$ & $0,18 a b$ & $0,19 b$ & 0,01 & 13,35 \\
\hline $\begin{array}{l}\text { Ácido oléico } \\
\text { C18:1, } \omega-9 \text { cis }\end{array}$ & $1,75 \mathrm{a}$ & $2,10 \mathrm{a}$ & $1,47 a$ & $1,63 a$ & $1,55 a$ & 0,24 & 24,43 \\
\hline $\begin{array}{l}\text { Ácido } 11 \text {-cis-ecosenóico } \\
\text { C20:1, } \omega-9 \text { cis }\end{array}$ & $0,02 \mathrm{a}$ & $0,03 a$ & $0,02^{\mathrm{a}}$ & $0,02 \mathrm{a}$ & $0,02 \mathrm{a}$ & 0,002 & 16,60 \\
\hline Total MUFA & $1,95 a$ & $2,31 \mathrm{a}$ & $1,61^{\mathrm{a}}$ & $1,83 a$ & $1,76 \mathrm{a}$ & 0,10 & 20,01 \\
\hline \multicolumn{8}{|c|}{ Coxa/sobrecoxa } \\
\hline $\begin{array}{l}\text { Ácido miristoléico } \\
\text { C14:1, } \omega-9 \text { cis }\end{array}$ & $0,02 \mathrm{a}$ & $0,03 a$ & $0,02 \mathrm{a}$ & $0,02 \mathrm{a}$ & $0,02 \mathrm{a}$ & 0,03 & 22,13 \\
\hline $\begin{array}{l}\text { Ácido palmitoléico } \\
\text { C16:1, } \omega-7 \text { cis }\end{array}$ & 1,08ab & $1,11 \mathrm{ab}$ & $0,87 a$ & $1,29 b$ & $1,30 \mathrm{~b}$ & 0,09 & 13,30 \\
\hline $\begin{array}{l}\text { Ácido oléico } \\
\text { C18:1, } \omega-9 \text { cis }\end{array}$ & $7,71 \mathrm{a}$ & $7,02 \mathrm{a}$ & $7,10 \mathrm{a}$ & $7,61 \mathrm{a}$ & $7,62 \mathrm{a}$ & 0,85 & 19,92 \\
\hline $\begin{array}{l}\text { Ácido } 11 \text {-cis-eicosenóico } \\
\text { C20:1, } \omega-9 \text { cis }\end{array}$ & $0,09 a$ & $0,09 a$ & $0,10 \mathrm{a}$ & $0,09 a$ & $0,10 \mathrm{a}$ & 0,01 & 24,87 \\
\hline Total MUFA & $8,90 \mathrm{a}$ & $8,25 a$ & $8,09 a$ & $9,01 \mathrm{a}$ & $9,04 \mathrm{a}$ & 0,08 & 15,02 \\
\hline
\end{tabular}

Medidas na linha seguidas de letras iguais não diferem $(P>0,05)$ significativamente pelo teste Tukey.

As análises são expressas em base de matéria seca.

Segundo Van Heerden et al. (2002), que estudaram a composição química de frangos vendidos no comércio da África do Sul, observaram no peito quantidades de ácido palmitoléico $(0,12 \mathrm{~g} / 100 \mathrm{~g})$ semelhantes e inferiores de ácido oléico (1,02 g/100 g), dados que corroboram os obtidos neste trabalho. Estes valores inferiores possivelmente foram ocasionados pelos ingredientes utilizados nas dietas daquelas aves, que poderiam conter menor concentração desse ácido graxo. Hulan et al. (1989), no entanto, estudando a composição da carne de frango observaram, em ambos os cortes, que o ácido graxo monoinsaturado mais encontrado foi o ácido oléico (4,51 g/100 g). Quando esses autores avaliaram frangos alimentados com 0, 4, 8 e 12\% de farinha de peixe, observaram aumento linear desse ácido graxo.

A modificação no perfil lipídico de alguns ácidos graxos na carne dos frangos (Tabela 6) confirma resultados que indicam que o perfil de ácidos graxos $\omega$-3 poliinsaturados pode ser modificado com a inclusão farinha de peixe na ração (Miller et al., 1969; Ratnayake et al., 1989).

Não houve diferença significativa no teor de ácido graxo linoléico carne do peito dos frangos entre as rações (Tabela 6). Contudo, as aves alimentadas com 9\% de farinha de peixe apresentaram maior teor de ácido graxo 
$\alpha$-linolênico em comparação àquelas alimentadas com rações com aveia branca, o que está de acordo com o perfil de ácidos graxos das rações (Tabela 2), pois naquelas com 9\% de farinha de peixe os valores de ácido graxo $\alpha$-linolénico eram muito superiores (4,95\%) em relação àquelas com $10 \mathrm{e}$ $20 \%$ de aveia (2,08 e 2,12, respectivamente).

A ração com $9 \%$ de farinha de peixe proporcionou aumento significativo do ácido graxo linoléico $(\omega-6)$ na coxa/sobrecoxa em relação às rações com aveia-branca (Tabela 6). A inclusão de $9 \%$ de farinha de peixe aumentou significativamente a quantidade desse ácido graxo na carne, o que é considerado nutricionalmente bom para os consumidores dessa carne. Esse resultado está relacionado à maior concentração desses ácidos nas rações com $9 \%$ de farinha de peixe (Tabela 2), portanto, é possível o enriquecimento da carne de frango com rações com teores mais altos desses ácidos graxos.

A razão de $A G \omega 6 / \omega 3$ na carne de frango, em ambos os cortes, foi maior nos animais alimentados com as rações contendo aveia-branca. As demais rações resultaram em menor relação, mesmo assim, continham níveis bem acima do máximo recomendado, de 5, para a dieta total, o que confirma a necessidade de compensar esta deficiência na dieta com outros alimentos ricos em C18:3, $\omega$-3.

Nos dois cortes de frango avaliados, o nível de 9\% de farinha de peixe foi o que promoveu melhor relação poliinsaturados/saturados.

Os resultados obtidos neste trabalho diferem dos obtidos em pesquisas com carne de frango, realizadas por Bragagnolo \& Rodriguez-Amaya (1992, 1995), que relataram concentrações de PUFA na carne do peito de $0,54 \mathrm{~g} / 100 \mathrm{~g}$ e na coxa/sobrecoxa de 1,39 g/100 g.

Souza et al. (1999) analisaram a composição de ácidos graxos da carne de frango assada e verificaram, tanto na coxa como no peito sem pele, valores inferiores C18:2 e C18:3 (1,68 e 0,11 g/100 g para coxa, respectivamente, e 0,41 e $0,03 \mathrm{~g} / 100 \mathrm{~g}$ para o peito, respectivamente), e relação poliinsaturados/saturados superiores (1,07 na coxa e 0,91 no peito). Segundo os autores, entre os ácidos graxos PUFA, o que apareceu em maior quantidade foi o ácido linoléico (C18:2, $\omega-6)$, encontrado em maior quantidade na coxa. Esse resultado é normal, uma vez que o peito dos frangos não é tecido de armazenamento de gordura.

Foram observados valores semelhantes no peito de ácido linoléico aos obtidos por Van Heerden et al. (2002), que avaliaram a composição química de frangos, porém inferiores de ácido linolênico (C18:3), na coxa observaram resultados superiores de C18:2 e inferiores de C18:3.

Resultados de aumento de $\omega$-3 semelhantes aos obtidos neste experimento podem ser observados nos estudos de Ratnayake et al. (1989), que pesquisaram frangos alimentados com 4, 8 e 12\% de farinha de peixe. Quando se elevou a quantidade de farinha de peixe, houve acréscimo de AG $\omega$-3 poliinsaturados, com nível decrescente de AG $\omega$-6. Porém, neste estudo, encontrou-se elevação, também, na quantidade de AG $\omega-6$, no corte de coxa/sobrecoxa, contrariando o trabalho dos autores citados.

A ração contendo maior quantidade total de ácidos graxos saturados e monoinsaturados foi àquela contendo 9\% de farinha de peixe (Tabela 2) seguida daquela com 4,5\%.

Tabela 6 - Composição química de ácidos graxos poliinsaturados (g/100 g) da carne de peito e sobrecoxa dos frangos avaliados

\begin{tabular}{|c|c|c|c|c|c|c|c|}
\hline \multirow[t]{2}{*}{ Ácido graxo } & \multirow[t]{2}{*}{ Ração-referência } & \multicolumn{2}{|c|}{ Farinha de peixe (\%) } & \multicolumn{2}{|c|}{ Aveia-branca (\%) } & \multirow[t]{2}{*}{ Erro-padrão da média } & \multirow[t]{2}{*}{ CV (\%) } \\
\hline & & 4,5 & 9 & 10 & 20 & & \\
\hline & \multicolumn{7}{|c|}{ Peito } \\
\hline $\begin{array}{l}\text { Ácido linoléico } \\
\text { C18:2, } \omega-6\end{array}$ & $0,98 a$ & $1,09 \mathrm{a}$ & $1,20 \mathrm{a}$ & $0,74 a$ & $0,71 \mathrm{a}$ & 0,14 & 25,11 \\
\hline $\begin{array}{l}\text { Ácido } \alpha \text {-linolênico } \\
\text { C18:3, } \omega \text {-3 }\end{array}$ & $0,07 a b$ & $0,07 a b$ & $0,10 \mathrm{~b}$ & $0,04 \mathrm{a}$ & $0,04 a$ & 0,01 & 29,74 \\
\hline Total PUFA & $1,05 a$ & $1,16 \mathrm{a}$ & $1,30 \mathrm{a}$ & $0,78 \mathrm{a}$ & $0,75 a$ & 0,05 & 27,52 \\
\hline Relação $\omega 6 / \omega 3$ & $14,00 \mathrm{~b}$ & $15,60 \mathrm{~b}$ & $12,00 \mathrm{~b}$ & $18,50 \mathrm{a}$ & $17,80 \mathrm{a}$ & 0,20 & 16,02 \\
\hline \multirow[t]{2}{*}{ Relação Poli/Satur } & $0,88 \mathrm{~b}$ & $0,72 b$ & $1,25 \mathrm{a}$ & $0,62 b$ & $0,69 b$ & 0,06 & 23,21 \\
\hline & \multicolumn{7}{|c|}{ Sobrecoxa } \\
\hline $\begin{array}{l}\text { Ácido linoléico } \\
\text { C18:2, } \omega-6\end{array}$ & $4,27 a b$ & $4,11 \mathrm{ab}$ & $6,01 \mathrm{~b}$ & $3,32 \mathrm{a}$ & 3,03a & 0,48 & 19,95 \\
\hline $\begin{array}{l}\text { Ácido } \alpha \text {-linolênico } \\
\text { C18:3, } \omega \text {-3, }\end{array}$ & $0,30 \mathrm{a}$ & $0,30 \mathrm{a}$ & $0,52 b$ & $0,18 \mathrm{a}$ & $0,17 \mathrm{a}$ & 0,03 & 20,82 \\
\hline Total PUFA & $4,57 \mathrm{a}$ & $4,41 \mathrm{a}$ & $6,53 a$ & $3,50 \mathrm{a}$ & $3,20 \mathrm{a}$ & 0,20 & 25,61 \\
\hline Relação $\omega 6 / \omega 3$ & $14,20 b$ & $13,70 b$ & $11,50 \mathrm{~b}$ & $18,40 \mathrm{a}$ & $17,80 \mathrm{a}$ & 0,05 & 19,02 \\
\hline Relação Poli/Satur & $0,83 b$ & $0,79 b$ & $1,16 \mathrm{a}$ & $0,59 b$ & $0,52 b$ & 0,04 & 20,03 \\
\hline
\end{tabular}

Medidas na linha seguidas de letras iguais não diferem $(P>0,05)$ significativamente pelo teste Tukey.

As análises são expressas em base de matéria seca. 
O alto nível de ácidos graxos saturados era esperado, uma vez que os produtos de origem animal contêm, por natureza, maior quantidade destes ácidos graxos em sua composição. A ração contendo 9\% de farinha de peixe foi a que apresentou maior nível destes ácidos graxos poliinsaturados, seguida daquelas com $4,5 \%$. A melhor relação $\omega 6 / \omega 3$ foi encontrada na ração com $9 \%$ de farinha de peixe e a mais alta, considerada de pior qualidade à saúde, foi obtida na ração contendo $20 \%$ de aveia-branca. A ração com a melhor relação poliinsaturados/saturados foi a ração-referência. A ração contendo $9 \%$ de farinha de peixe apresentou a pior relação e maior quantidade de ácidos graxos saturados.

Segundo Newman et al. (2002), a relação poliinsaturados/ saturados pode estar relacionada à porcentagem de ácidos graxos monoinsaturados da dieta ou à ingestão de ácidos graxos específicos, hipótese confirmada neste estudo, pois a ração contendo 9\% de farinha de peixe (Tabela 2) apresentou 33,9 g/100 g ácidos graxos MUFA e, nos dois cortes avaliados, essa ração induziu a maior relação de poliinsaturados/ saturados. Ressalta-se que o consumo total de ração nesse experimento foi o mesmo para todas as rações.

Observa-se que a relação poliinsaturados/saturados da carne das aves alimentadas com $9 \%$ de farinha de peixe foi a maior, portanto, é a mais indicada para consumo (Department of Health, 1994).

Os resultados relacionados à quantidade total de ácidos graxos saturados, MUFA e PUFA no peito foram superiores aos informados na Tabela da USDA (1999), de 0,44; 0,39 e 0,37g/100 g e, na coxa/sobrecoxa, 1,10; 1,34 e 1,07 g/100 g, respectivamente. Na Tabela TACO (2004), no entanto, a quantidade de ácidos graxos saturados peito é de 1,10/100 g e, na coxa/sobrecoxa, o total de ácidos graxos saturados, MUFA e PUFA, 3,0; 4,5 e 1,6 g/100 g. Essa discrepância entre os resultados demonstra a grande variação entre as análises, dietas e animais avaliados o que exige maior número de pesquisas na área.

\section{Conclusões}

A inclusão de farinha de peixe e aveia-branca em rações à base de milho e farelo de soja, nos níveis 9 e $10 \%$, respectivamente, provoca acúmulo de gordura na coxa/ sobrecoxa de frangos de corte. Rações contendo $20 \%$ de aveia-branca promovem maior acúmulo de ácido graxo palmitoléico na carne de peito de frangos. A inclusão de $9 \%$ de farinha de peixe em rações à base milho e farelo de soja ocasiona aumento nos níveis de ácidos graxos poliinsaturados da série $\omega$-3. Rações com aveia-branca propiciam aumento na relação de ácidos graxos das séries $\omega-6 / \omega-3$.

\section{Agradecimento}

À Empresa Brasileira de Pesquisa Agropecuária Embrapa Suínos e Aves, de Concórdia, Santa Catarina, pela parceria nas análises químicas, e à Indústria Agrária de Entre Rios, pelas rações e pelos pintinhos.

\section{Literatura Citada}

ASSOCIATION OF OFFICIAL ANALYTICAL CHEMISTS - AOAC. Protein (crude) in animal feed. In: Official methods of analysis of AOAC international. 16.ed. method 976.06 G.H. Arlington: Patricia Cunniff. 1995a. v.1, p.7-9.

ASSOCIATION OF OFFICIAL ANALYTICAL CHEMISTS - AOAC. Fat (crude) or ether extract in animal feed. In: Official Methods of Analysis of AOAC International. 16.ed. Arlington: Patricia Cunniff, 1995b. v.1, p.17.

BONANOME, A.M.D.; GRUNDY, S.M. Effect of dietary stearic acid on plasma cholesterol and lipoprotein levels. The New England Journal of Medicine, v.318, n.19, p.1244-1248, 1988.

BRAGAGNOLO, N.; RODRIGUEZ-AMAYA, D.B. Teores de colesterol em carne de frango. Revista Farmácia Bioquímica, v.28, p.122-131, 1992.

BRAGAGNOLO, N.; RODRIGUEZ-AMAYA, D.B. Teores de colesterol em carne suína e bovina e efeito do cozimento. Ciência e Tecnologia de Alimentos, v.15, p.11-17, 1995.

BRAGAGNOLO, N. [2001]. II Conferência Internacional Virtual sobre Qualidade de Carne Suína. Aspectos comparativos entre carnes segundo a composição de ácidos graxos e teor de colesterol. Disponível em: <www.cnpsa. embrapa.br/sgc/ sgc_publicacoes/anais01cv2_pt.pdf> Acesso em: 23/3/2005.

BUTOLO, J.E. Qualidade de ingredientes na alimentação animal. Campinas: Colégio Brasileiro de Alimentação Animal, 2002. 430p.

CERES - LAB. DE CIÊnCIAS E TEC. DE CEREAIS. Aveia Disponível em: <http://www.cca.ufsc.br/dcal/labs/ceres/aveia. html\#carac> Acesso em: 18/3/2005.

DENKER, M.A. Effects of cocoa butter on serum lipids in humans historical higlihts. The American Journal of Clinical Nutrition, v.60, p.1014-1020, 1994.

DEPARTMENT OF HEALTH. Nutritional aspects of cardiovascular disease. London: Her Majesty's Stationery Office, 1994. 178p. (Report on health and social subjects, 46).

FERREIRA, D.F. SISVAR - Sistema de análise de variância Versão 4.6., Lavras: UFLA, 1999. (CD-ROM).

FIALHO, E.T. Alimentos alternativos para suínos. Lavras: UFLA/FAEPE, 2004. 206p.

GRANDE, F. Dog serum lipid responses to dietary fats differing in the chain length of the saturated fatty acids. Journal of Nutrition, v.76, p.255-264, 1962.

HARGIS, P.S.; Van ELSWYK, M.E.; HARGIS, B.M. Dietary modification of yolk lipid with menhaden oil. Poultry Science, v.70, n.4, p.874-883, 1991.

HARTMAN, L.; LAGO, R.C.A. Rapid preparation of fatty acids methyl esters. London: Laboratory Pratice, 1986. v.22, p. $475-476$

HULAN, H.W.; ACKMAN, R.G.; RATNAYAKE, W.M.N. et al. Omega-3 fatty acid levels and general performance of commercial broilers fed practical levels of redfih meal. Poultry Science, v.68, p.153-162, 1989

INSTITUTO ADOLFO LUTZ. Normas analíticas - Métodos químicos e físicos para análise de alimentos. São Paulo: Instituto Adolfo Lutz, v.1, 1985. 533p.

KATCH, F.I.; McARDLE, W.D. Nutrição, exercício e saúde. 4.ed. Rio de Janeiro: Medsi, 1996. 657p. 
KEYS, A.; ANDERSON, J.T. GRANDE, F. Serum cholesterol response to changes in the diet. IV. Particular saturated fatty acids in the diet. Metabolism, v.14, p.776-780, 1965.

KINSELLA, J.E.; LOKESH, B.; STONE, R.A. Dietary n-3 polyunsaturated fatty acids and amelioration of cardiovascular disease: possible mechanisms. American Journal Clinical Nutrition, v.52, p.1-28, 1990.

KRUMMEL, D. Nutrição na doença cardiovascular. In: MAHAN, L.K.; ESCOTT-STUMP, S. (Eds.) Alimentos, nutrição \& dietoterapia. 9.ed. São Paulo: Roca, 1998. p.525-567.

MAcLEOD, M.G.; MCNEILL, L.; BERNARD, K. et al. Performance and egg quality in laying hens fed on naked oats. The use of oats in animals feeds. Midlothian: Roslin Institute, 2004. 300p.

MAHAN, L.K.; ARLIN, M.T. Krause: alimentos, nutrição e dietoterapia. São Paulo: Roca, 1994. 957p.

MATHERSON, B.; WALTER, K.Z.; TAYLOR, D. McD. et al. Effects serum lipids of monounsaturated oil and margarine in the diet of an Antarctic expedition. The American Journal of Clinical Nutrition, v.63, p.933-941, 1996.

MILLER, D.; LEONG, K.C.; SMITH, P. Effect of feeding and withdrawal of menhaden oil on the w3 and w6 fatty acid content of broiler tissue. Journal of Food Science, v.34, p.136 $141,1969$.

MONTEIRO, J.B.R.; ROSADO, L.E.F.P.L. Nutrição e doenças cardiovasculares. 2.ed. Viçosa, MG: Universidade Federal de Viçosa, 1993. 147p.

MONTEIRO, A.L.G.; MORAES, A.; CORRÊA, E.A.S. et al. Forragicultura no Paraná. Londrina: Comissão Paranaense de Avaliação de Forrageiras, 1996. 292p.

NEWMAN, R.E.; BRYDEN, W.L.; FLECK, E. et al. Dietary n-3 and n-6 fatty acids alter avian metabolism: metabolism and abdominal fat deposition. British Journal of Nutrition, v.88, p.11-18, 2002.

OLIVEIRA, J.E.D.; SANTOS, A.E.; WILSON, E.D. Nutrição básica. 1.ed. São Paulo: Almed, 1992. 93p.
OLIVEIRA, J.E.D.; MARCHINI, J.S. Ciências nutricionais. São Paulo: Sarvier, 1998. 403p.

RAFAELLI, D.R.; BOAS, M.A.V.; SILVA, E.T. et al. Análise da qualidade quanto à acidez do óleo de frango utilizado para a fabricação de ração. Ciência e Agrotecnologia, v.25, n.3, p.641-645, 2001.

RATNAYAKE, W.M.N.; ACKMAN, R.G.; HULAN, H.W. Effect of redfish meal enriched diets on the taste and n-3 PUFA of 42 day-old broilers chickens. Journal of the Science of Food and Agriculture, v.49, p.59-74, 1989.

RIBEIRO, P.A.P.; GOMIERO, J.S.G.; LOGATO, P.V.R. Manejo alimentar de peixes. Lavras: Núcleo de Estudos em Aquacultura, 2005. v.1, p.1-13. (Boletim Técnico).

ROSTAGNO, H.S.; ALBINO, L.F.T.; DONZELE, J.L. et. al. Tabelas brasileiras para aves e suínos: composição de alimentos e exigências nutricionais. Viçosa, MG: Universidade Federal de Viçosa, 2000.

SOUZA, S.A.B.; VISENTAINER, J.V.; MATSUSHITA, M. et al. Lipids and fatty acids in roasted chickens. Archivos Latinoamericanos de Nutricion, v.49, n.3, p.295-297, 1999.

TABELA BRASILEIRA DE COMPOSIÇÃO DE ALIMENTOS - TACO. Núcleo de Estudos e Pesquisas em Alimentação. Campinas: UNICAMP, 2004. 44p.

TORRES, E.A.F.S.; CAMPOS, N.C.; DUARTE, M. et al. Composição centesimal e valor calórico de alimentos de origem animal. Ciência e Tecnologia de Alimentos, v.20, n.2, p.145-150, 2000.

UNITED STATES DEPARTMENT OF AGRICULTURE - USDA. Nutrient database for standard reference. Release 13, NDB n.10199, 1999. (CD-ROM).

Van ELSWYK, M.E.; HARGIS, B.M.; WILLIAMS, J.D. et al. Dietary menhaden oil contributes to hepatic lipidosis in laying hens. Poultry Science, v.73, p.653-662, 1994.

Van HEERDEN, S.M.; SCHONFELDT, H.C.; SMITH M.F. et al. Nutrient content of South African chickens. Journal of Food Composition and Analysis, v.15, p.47-64, 2002. 